\title{
Desempenho de gotejadores operando com lixiviado de aterro sanitário
}

Com a instituição da Política Nacional de Resíduos Sólidos no Brasil, espera-se que o número de aterros sanitários aumente, ao longo dos anos, e com isso a necessidade do desenvolvimento de técnicas de tratamento e, ou aproveitamento dos percolados. Objetivou-se, com este trabalho, analisar o efeito da aplicação de percolado de aterro sanitário diluído sobre a vazão nominal dos gotejadores das unidades de irrigação por gotejamento após 160 horas de funcionamento. 0 experimento foi conduzido sob delineamento inteiramente casualizado no esquema de parcelas subdivididas, tendo nas parcelas os tipos de gotejadores ( $G 1$ - 1,6 L h-1; G2 - 2,0 L h-1, G3 - 4,0 L h-1 e G4 - 8,0 L h-1) e nas subparcelas os tempos de operação $(0,20,40,60,80,100,120,140$ e 160 h), com quatro repetições. A vazão do sistema (Q) foi obtida a cada $20 \mathrm{~h}$ de operação do sistema, até completar $160 \mathrm{~h}$ de funcionamento em todas as unidades de irrigação. Houve diferença estatística dos níveis de obstrução do gotejador G1 (não autocompensante) em relação aos demais, indicando menor suscetibilidade ao entupimento dos gotejadores G2, G3 e G4 (autocompensantes). Os valores de Q aprontaram o gotejador G1 como o mais sensível ao entupimento.

Palavras-chave: Percolado; Emissores; Membranas.

\section{Performance of drippers operating with landfill percolate}

With the establishment of the National Solid Waste Policy in Brazil, it is expected that the number of landfills will increase, over the years, and with this the need to develop treatment techniques and, or use of percolates. The objective of this work was to analyze the effect of the application of diluted landfill leachate on the nominal flow of drippers from drip irrigation units after 160 hours of operation. The experiment was conducted under a completely randomized design in the split plot scheme, with the types of drippers in the plots (G1 - 1.6 L h-1; G2 - 2.0 L h-1, G3 - 4.0 L h-1 and G4 - 8.0 L h- 1 ) and in the subplots the operating times (0, 20 , $40,60,80,100,120,140$ and $160 \mathrm{~h}$ ), with four repetitions. The system flow (Q) was obtained after every $20 \mathrm{~h}$ of system operation, until completing $160 \mathrm{~h}$ of operation in all irrigation units. There was a statistical difference in the levels of obstruction of dripper G1 (non-self-compensating) in relation to the others, indicating less susceptibility to clogging of drippers G2, G3 and G4 (self-compensating). The Q values made the G1 dripper the most sensitive to clogging.

Keywords: Percolate; Emitters; Membranes.

Francisco de Oliveira Mesquita (iD Instituto Nacional do Semiárido, Brasil http://lattes.cnpq.br/2630263044186621 http://orcid.org/0000-0002-8580-079X

mesquitaagro@yahoo.com.br

\section{Rafael Oliveira Batista (iD)}

Universidade Federal Rural do Semiárido, Brasil http://lattes.cnpq.br/6747258062404427 http://orcid.org/0000-0002-3083-6808 rafael.oliveira@ufersa.gov.edu.br

\section{Lourival Ferreira Cavalcante (id}

Universidade Federal da Paraíba, Brasil http://lattes.cnpq.br/3065449647572057 http://orcid.org/0000-0002-8827-4713 lofeca@hotmail.com

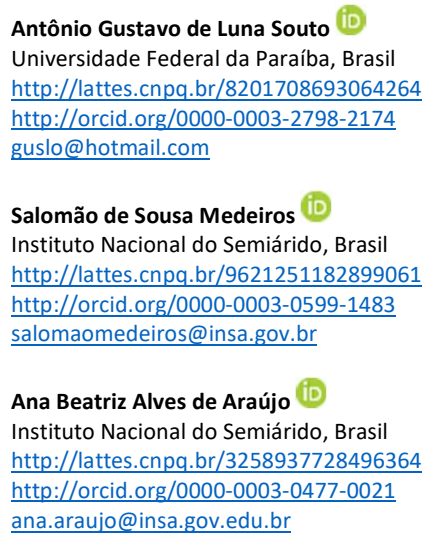

Fabiana Xavier Costa (iD

Instituto Nacional do Semiárido, Brasil http://lattes.cnpq.br/7399638770736678 http://orcid.org/0000-0001-7892-5036

fabiana.xavier@insa.gov.edu.br

\section{Referencing this:}

MESQUITA, F. O.; BATISTA, R. O.; CAVALCANTE, L. F.; SOUTO, A. G. L.; MEDEIROS, S. S.; ARAÚJO, A. B. A.; COSTA, F. X.. Desempenho de gotejadores operando com lixiviado de aterro sanitário. Revista Ibero Americana de Ciências Ambientais, v.11, n.6, p.522-531, 2020. DOI: http://doi.org/10.6008/CBPC2179-6858.2020.006.0042 


\section{INTRODUÇÃO}

Os resíduos sólidos urbanos despertam grande preocupação ambiental na sociedade moderna, devido às grandes quantidades geradas e as formas inadequadas de disposição no ambiente, que podem causar sérios problemas como a geração de odores, poluição ambiental e a proliferação de insetos e roedores transmissores de doenças ao ser humano (SETIYANTO et al., 2012; ALMEIDA et al., 2018).

Os lixiviados de aterros de resíduos sólidos urbanos são resultados da interação entre o processo de biodegradação da fração orgânica desses resíduos e da infiltração de águas pluviais que percolam e solubilizam componentes orgânicos e inorgânicos (RENOU et al., 2008). O lixiviado apresenta composição temporal e espacial variável e depende das características físicas do local de disposição dos resíduos (GOMES et al., 2018). Segundo Celere et al. (2007), o resíduo sólido urbano possui composição bastante variada, resultante, principalmente, das características ambientais e socioeconômicas da população que o gera. Fatores como clima, variações sazonais, grau de educação, poder aquisitivo, hábito e costumes influenciam na sua composição.

Dentre as tecnologias adotadas para a disposição final dos resíduos sólidos urbanos, o aterro sanitário se destaca por coletar e tratar o lixiviado e o gás metano gerados nas células do aterro, durante o período de operação e desativação deste empreendimento (SOLIANI et al., 2019). Os lixiviados de aterros sanitários são resultantes da interação entre o processo de biodegradação da fração orgânica dos resíduos sólidos urbanos e da infiltração de águas pluviais que percolam e solubilizam componentes orgânicos e inorgânicos (MATOS et al., 2013; GOMES et al., 2018).

O manejo adequado dos resíduos sólidos é uma importante estratégia de preservação do meio ambiente, assim como de promoção e proteção da saúde, visto que estes resíduos podem comprometer a qualidade do solo, da água e do ar, por serem fontes de compostos orgânicos voláteis, pesticidas, solventes e metais pesados, entre outros (LO MONACO et al., 2009; UEHARA et al., 2019).

Mesmo utilizando tecnologias apropriadas, o manejo de resíduos sólidos ainda enfrenta sérias limitações. A disposição no solo, mesmo que em aterros sanitários com captação de gases e efluentes esbarra no esgotamento de áreas físicas apropriadas para esse fim (JACOBI et al., 2011; KLEIN et al., 2018), principalmente nos grandes centros urbanos, implicando no deslocamento desses resíduos por longas distâncias, com os consequentes transtornos associados ao transporte (poluição, acidentes e outros).

A irrigação localizada se destaca para aplicação de águas residuárias pela elevada eficiência de aplicação do efluente, minimização do escoamento superficial e da percolação, redução dos teores de sais próximo ao sistema radicular das plantas e prevenção da formação de aerossóis (HERMES et al., 2020). No entanto, a grande vulnerabilidade da aplicação de águas residuárias pela irrigação localizada, consiste na alta suscetibilidade ao entupimento dos gotejadores em função do nível de tratamento do efluente (COSTA et al., 2019) e das características internas dos emissores (BATISTA et al., 2018).

Como consequência do entupimento dos gotejadores tem-se a alteração da vazão e a redução da uniformidade de aplicação (SILVA et al., 2019), resultando na perda de eficiência do sistema de irrigação, 
aumento do custo operacional e redução da produtividade do cultivo agrícola (SONG et al., 2017). O entupimento dos emissores reduz a vazão e, consequentemente, diminui a uniformidade de aplicação de efluentes de sistemas de irrigação localizada (BATISTA et al., 2018).

O grande problema associado à utilização de águas residuárias em sistemas de irrigação localizada consiste na modificação da vazão pelo entupimento parcial ou total dos gotejadores e como está afeta a uniformidade de distribuição de água (FERNANDES et al., 2014; BATISTA et al., 2018). O entupimento dos emissores de sistemas de irrigação ou até a sensibilidade ao problema de entupimento varia com as características do gotejador, qualidade da água relacionada aos aspectos físicos, químicos e biológicos (SILVA et al., 2019). Puig-Barguéset et al. (2010) analisaram o desempenho de três unidades de irrigação por gotejamento, dotadas de gotejador não-autocompensante com vazão nominal de $1,9 \mathrm{~L} \mathrm{~h}^{-1}$ e operando com esgoto doméstico tratado. Dois sistemas de irrigação, um com filtro de discos e outro com filtro de tela, ambos de $130 \mu \mathrm{m}$, foram abastecidos com esgoto doméstico secundário.

Do ponto de vista ambiental, os sistemas de irrigação por gotejamento são os mais sustentáveis para a disposição de águas residuárias. Isso é consequência da elevada eficiência de aplicação desses sistemas, do baixo risco de contaminação do produto agrícola e de operadores no campo, da minimização dos riscos de escoamento superficial, percolação e acumulação de sais próximo ao sistema radicular e da prevenção de aerossóis (CUNHA et al., 2017).

Diante o exposto, analisar o efeito da aplicação de percolado de aterro sanitário diluído sobre a vazão nominal dos gotejadores das unidades de irrigação por gotejamento após 160 horas de funcionamento.

\section{MATERIAIS E MÉTODOS}

Este trabalho foi realizado no período de 21 de agosto a 10 de outubro de 2017, na Unidade Experimental de Reuso de Água (UERA), da Universidade Federal Rural do Semi - Árido (UFERSA), em Mossoró-RN.

O experimento foi montado em esquema de parcelas subdivididas, tendo, nas parcelas, os modelos de gotejadores (G1, G2, G3 e G4) e, nas subparcelas, os períodos das avaliações $(0,20,40,60,80,100,120$, 140 e 160 horas), com quatro repetições (cada linha lateral representou uma repetição), conforme a metodologia proposta por Mesquita et al. (2016).

Para a realização dos ensaios experimentais montou-se uma bancada constituída por um reservatório de 0,5 $\mathrm{m}^{3}$ para armazenamento do percolado de aterro sanitário (PAS), um reservatório de 10 $\mathrm{m}^{3}$ para armazenamento da água da rede de abastecimento (AA), um reservatório de 5,0 $\mathrm{m}^{3}$ para armazenamento da mistura do PAS e da AA e uma plataforma construída em alvenaria e concreto, nas dimensões de 2,0 $\mathrm{m}$ de largura por 8,0 $\mathrm{m}$ de comprimento, tendo piso impermeabilizado uma canaleta lateral para recirculação do efluente, como apresentado na Figura 1. 


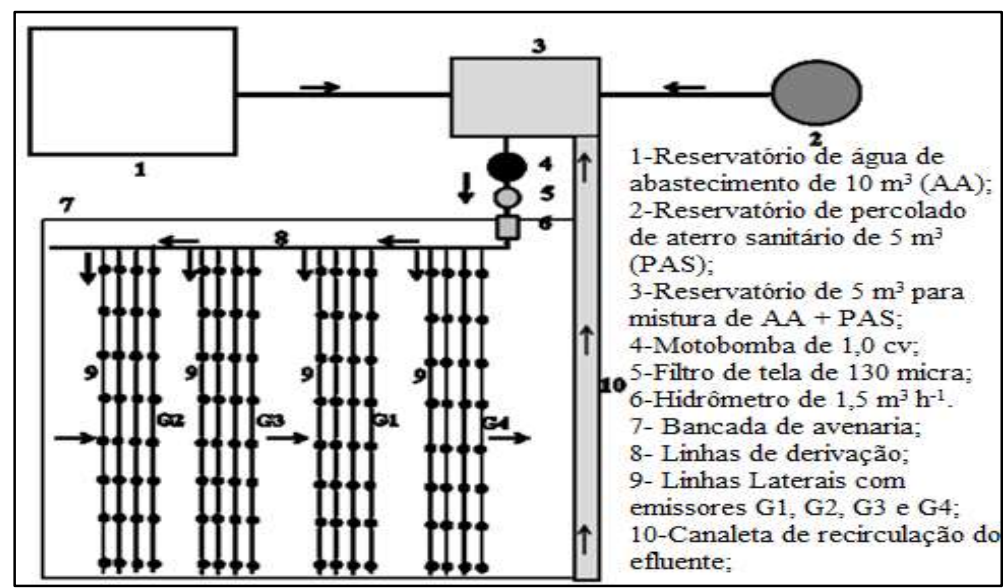

Figura 1: Esquema da bancada experimental, destacando todos os seus componentes para armazenamento, condução e recirculação do percolado de aterro sanitário diluído.

$\mathrm{Na}$ linha de derivação foram instalados 16 conectores com borracha de vedação, onde foram inseridas quatro linhas laterais por tipo de gotejador (cada linha lateral representou uma repetição). Em cada linha lateral foram marcados nove gotejadores para avaliação do desempenho hidráulico, totalizando 144 gotejadores avaliados nas quatro unidades de gotejamento, a cada $20 \mathrm{~h}$ até completar o tempo de operação de $160 \mathrm{~h}$. As linhas laterais, com $8 \mathrm{~m}$ de comprimento, foram instaladas em nível sobre o piso da plataforma (Figura 2).
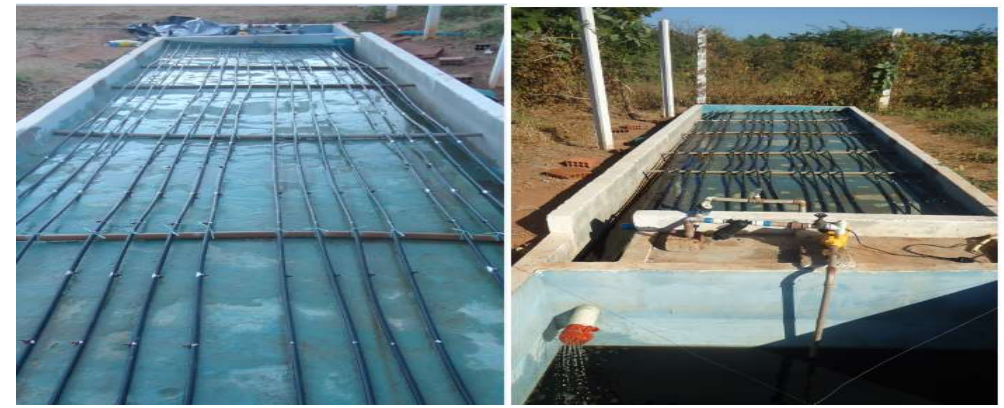

Figura 2: Plataforma da bancada experimental e sistemas de irrigação operando com percolado de aterro sanitário.

No interior da plataforma foram montadas quatro unidades de gotejamento, composta por um conjunto motobomba de 1,0 cv, um hidrômetro de 1,5 $\mathrm{m}^{-1} \mathrm{~h}^{-1}$, um filtro de tela com aberturas de $130 \mu \mathrm{m}$, uma de linha de derivação com diâmetro nominal de 32 mm de PVC e PN 40 e 16 linhas laterais de polietileno, com diâmetro nominal de $16 \mathrm{~mm}$, dotadas de quatro tipos de gotejadores, conforme apresentado na Figura 3.
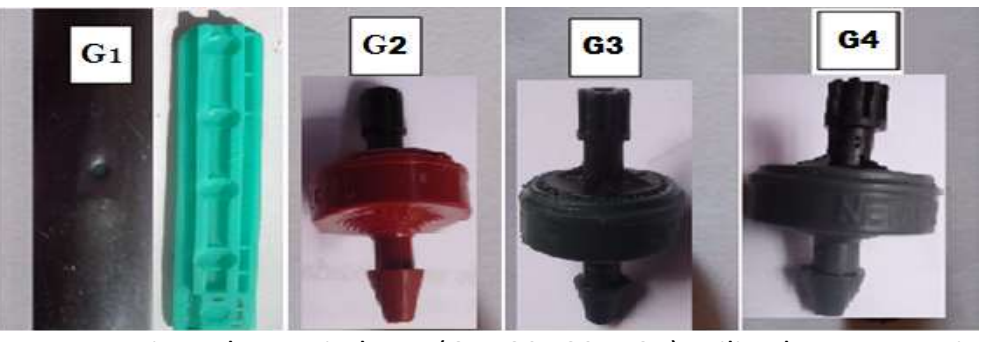

Figura 3: Imagem dos quatro tipos de gotejadores (G1, G2, G3 e G4) utilizados nos ensaios experimentais do desempenho hidráulico dos gotejadores aplicando percolado de aterro sanitário diluído em água de abastecimento.

Os quatro tipos de gotejadores utilizados nos ensaios experimentais foram escolhidos por serem os 
mais comercializados em Mossoró-RN e região, para a realidade do estado do rio Grande do Norte-RN, Brasil. Nesse sentido, este trabalho tem como foco principal o uso adequado da irrigação de diversos cultivos agrícolas e com o tipo de emissor ou gotejador adequado às realidades do semiárido brasileiro, principalmente, em parques recreativos, jardins e forragens. Na Tabela 1, estão apresentadas as principais informações técnicas dos gotejadores utilizados nos ensaios experimentais.

Tabela 1: Gotejadores (G) utilizados nos ensaios experimentais, destacando o fabricante (F), o dispositivo de autocompensação (DA), a vazão nominal (Q), o coeficiente de vazão (k), o expoente da vazão que caracteriza o regime de escoamento $(x)$, a área de filtragem $(A)$, o comprimento do labirinto $(L)$, o coeficiente de variação de fabricação $\left(C V_{f}\right)$, a faixa de pressão recomendada $(P)$ e o espaçamento entre emissores (EE).

\begin{tabular}{|c|c|c|c|c|c|c|c|c|c|c|}
\hline G & $\mathbf{F}$ & DA* & $\begin{array}{l}\mathbf{Q}^{*} \\
\left(\mathbf{L ~ h}^{-1}\right)\end{array}$ & $\mathbf{k}^{*}$ & $x^{*}$ & $\begin{array}{l}\text { A } \\
\left(\mathrm{mm}^{2}\right)\end{array}$ & $\begin{array}{l}\mathrm{L} \\
(\mathrm{mm})\end{array}$ & $\begin{array}{l}\mathrm{CV}_{\mathrm{f}}{ }^{*} \\
(\%)\end{array}$ & $\begin{array}{l}\text { P* } \\
\text { (kPa) }\end{array}$ & $\begin{array}{l}\mathrm{EE}^{*} \\
(\mathrm{~m})\end{array}$ \\
\hline G1 & Plastro Hydrodrip Super & Não & 1,65 & 0,53 & 0,48 & $4,0^{* *}$ & $37 * *$ & \pm 5 & $60-150$ & 0,30 \\
\hline G2 & Netafim PCJ-CNJ & Sim & 2,00 & 2,00 & 0,00 & $2,0^{*}$ & $35^{*}$ & \pm 7 & $50-400$ & 0,80 \\
\hline G3 & Netafim PCJ-CNJ & Sim & 4,00 & 4,00 & 0,00 & $2,0^{*}$ & $35^{*}$ & \pm 7 & $50-400$ & 0,80 \\
\hline G4 & Netafim PCJ-CNJ & Sim & 8,00 & 8,00 & 0,00 & $2,0^{*}$ & $35^{*}$ & \pm 7 & $50-400$ & 0,80 \\
\hline
\end{tabular}

Nota: * e ** informações obtidas nos catálogos dos fabricantes e informações medidas com auxílio de um parquímetro digital com precisão de 0,01 mm, respectivamente. CNJ - sistema anti-drenante.

Nota: * $\mathrm{e}^{* *}$ informações obtidas nos catálogos dos fabricantes e informações medidas com auxílio de um paquímetro digital com precisão de $0,01 \mathrm{~mm}$, respectivamente. PCJ - este mantém uma vazão uniforme mesmo sob diferentes pressões de entrada, assegurando uma distribuição exata da água e nutrientes, além disto, o emissor possui amplas seções de passagem da água e constante atuação do mecanismo de autolimpeza, que aumentam a sua resistência ao entupimento. CNJ - sistema anti-drenante.

O percolado (PAS) foi transportado de um reservatório superficial, situado no aterro sanitário do município de Mossoró-RN, próximo ao local do experimento, por meio de um recipiente plástico com capacidade armazenadora para $1 \mathrm{~m}^{3}$. Enquanto que a água de abastecimento (AA) foi oriunda da Companhia de Águas e Esgotos do Rio Grande do Norte (CAERN). O efluente foi armazenado em um reservatório de alvenaria com a capacidade máxima de $10 \mathrm{~m}^{3}$. Durante o período experimental, o PAS foi diluído em AA, na proporção de 1:3, no reservatório de $5,0 \mathrm{~m}^{3}$, para ser aplicado nas quatro unidades de gotejamento, quatro horas por dia, até completar $160 \mathrm{~h}$.

Em cada linha lateral das unidades de irrigação foram fixados nove gotejadores, espaçados a cada 0,80 m e 0,30 m entre as linhas laterais, totalizando 144 gotejadores em todo sistema, para a avaliação do desempenho hidráulico. A cada 20 h de operação das unidades de gotejamento mediu-se a vazão dos 144 gotejadores fixados por linha lateral. Na medição da vazão dos gotejadores utilizaram-se coletores plásticos de $200 \mathrm{~mL}$ e proveta de $100 \mathrm{~mL}$. Quantificou-se o volume aplicado de efluente pelos gotejadores, durante três minutos, conforme recomendado pela NBR ISO 9261 (ABNT, 2006). O cálculo da vazão (Q) foi obtido empregando-se a Equação 1.

$$
\mathrm{Q}=\frac{V}{1000 \times t} \cdot 60
$$

em que:

$\mathrm{Q}$ - vazão do gotejador, $\mathrm{L} \mathrm{h}^{-1}$; $\mathrm{V}$ - volume de efluente coletado, $\mathrm{mL}$; $\mathrm{t}$ - tempo de coleta do efluente, min.

A pressão de serviço foi mantida, diariamente, no valor de $140 \mathrm{kPa}$, utilizando-se um manômetro analógico de glicerina, graduado de 0 a $400 \mathrm{kPa}$, com classe de exatidão de $\pm 1 \%$ de fundo de escala conforme procederam também, Mesquita et al. (2016) e Batista et al. (2018). 
No período experimental, realizaram-se várias determinações das características físico-químicas e microbiológicas do percolado de aterro sanitário diluído e da água de abastecimento, inerentes ao risco de obstrução de gotejadores e inclusive a cada 20 horas de operação o indicador de desempenho hidráulico (Q). Para isto, as amostras foram coletadas a cada 20 h, após o sistema de filtragem, sendo posteriormente armazenadas em recipientes esterilizados, à temperatura de 4 ํㅡ em caixa isotérmica com gelo, até o momento da realização das análises em laboratórios da UFERSA.

Com a finalidade de minimizar os níveis de entupimento nos quatro tipos de gotejadores, a pressão de serviço das unidades de gotejamento foi mantida no valor de $140 \mathrm{kPa}$ por meio de manômetro, seguindo as recomendações de Coelho et al. (2015) para operação de unidade de gotejamento operando com percolado de aterro sanitário. A pressão de serviço foi medida, diariamente, com um manômetro de glicerina graduado de 0 a $400 \mathrm{kPa}$, tendo precisão de $10 \mathrm{kPa}$. Na análise de relação entre as variáveis do desempenho hidráulico e as características físico-químicas e microbiológica do percolado de aterro sanitário diluído em água de abastecimento, utilizou-se o teste de correlação de Pearson a 5\% de probabilidade.

Os dados foram submetidos à análise de variância (ANOVA), empregando-se o teste $\mathrm{F}$ a $5 \%$ de probabilidade. Para o fator qualitativo tipo de gotejadores, as médias foram comparadas, utilizando-se o teste Tukey, a 5\% de probabilidade. Para o fator quantitativo tempo de operação, os modelos de regressão simples e múltipla foram escolhidos com base na significância dos coeficientes de regressão, aplicando-se o teste t num nível de até $10 \%$, no coeficiente de determinação ( $260 \%)$ no processo em estudo (FERREIRA, 2011).

\section{RESULTADOS E DISCUSSÃO}

Na Tabela 2, encontra-se o resumo da análise de variância (ANOVA) da variável resposta vazão (Q) e análise dos fatores isolados Tipos de Gotejadores (G) e Tempo de Avaliação (T) bem como da interação G x T referente ao estudo no tempo das unidades gotejadoras $\mathrm{G1}, \mathrm{G} 2, \mathrm{G} 3$ e $\mathrm{G} 4$, ao longo de 160 horas de funcionamento do sistema de irrigação.

Tabela 2: Resumo da análise de variância obtidas da variável dependente $Q$, no esquema de parcelas subdivididas avaliados com 160 horas de operação do sistema.

\begin{tabular}{|c|c|c|}
\hline \multirow{2}{*}{ Fontes de variação } & GL & Vazão do sistema \\
\hline & \multicolumn{2}{|r|}{$Q\left(L^{-1}\right)$} \\
\hline Tipo de gotejador (G) & 3 & $289,99^{* *}$ \\
\hline Resíduo (a) & 9 & 0,685 \\
\hline Tempo de avaliação (T) & 8 & $0,0491^{*}$ \\
\hline $\mathrm{G} \times \mathrm{T}$ & 24 & $0,0742^{* *}$ \\
\hline Resíduo (b) & 99 & 0,0194 \\
\hline CV (\%) parcelas & - & 7,07 \\
\hline CV (\%) subparcelas & - & 3,77 \\
\hline
\end{tabular}

Os valores médios de $Q$ nas unidades gotejadoras, para os tempos de funcionamento inicial $(0 \mathrm{~h})$ e final (160 h), foram de 1,79 e 1,09 $\mathrm{L} \mathrm{h}^{-1}$ no gotejador $\mathrm{G} 1$, de 1,87 e 1,88 $\mathrm{L} \mathrm{h}^{-1}$ para o gotejador $\mathrm{G} 2$, de 3,86 e 3,70 $\mathrm{L} \mathrm{h}^{-1}$ no gotejador $\mathrm{G} 3$ e de 8,15 e 7,40 L h $\mathrm{h}^{-1}$ para o gotejador $\mathrm{G} 4$, como apresentado na Figura 1. 
Apresentam-se, na Tabela 3, as médias da vazão dos quatro gotejadores (Q) em função do tempo de avaliação. Os valores médios de $\mathrm{Q}$ dos gotejadores $\mathrm{G} 2$ e $\mathrm{G} 3$ não diferiram estatisticamente ao longo do período experimental, indicando maior resistência ao entupimento. Enquanto, os gotejadores G1 e G4 apresentaram diferenças estatísticas: a) com apenas $40 \mathrm{~h}$ de operação, os níveis de entupimento do gotejador G1 começaram a afetar o seu desempenho; e b) com apenas $20 \mathrm{~h}$ de funcionamento, o entupimento alterou o valor médio de $Q$ das unidades gotejadoras $\mathrm{G} 4$.

Tabela 3: Valores médios do $Q$ das unidades gotejadoras para o fator emissor dentro de cada nível de tempo de avaliação.

\begin{tabular}{|c|c|c|c|c|}
\hline \multirow{2}{*}{ Tempos de avaliação (horas) } & \multicolumn{4}{|c|}{ Tipo de gotejador } \\
\hline & G1 & G2 & G3 & G4 \\
\hline 0 & $1,75 a$ & $1,86 a$ & $3,75 a$ & $7,84 a b$ \\
\hline 20 & $1,76 a$ & $1,86 a$ & $3,78 a$ & $7,44 c$ \\
\hline 40 & $1,31 b$ & $1,78 a$ & $3,79 a$ & $7,77 a b c$ \\
\hline 60 & $1,51 \mathrm{ab}$ & $1,86 a$ & $3,80 a$ & $7,94 a$ \\
\hline 80 & $1,46 a b$ & $1,85 a$ & $3,78 a$ & 7,59abc \\
\hline 100 & $1,28 b$ & $1,84 a$ & $3,80 a$ & 7,69abc \\
\hline 120 & $1,47 a b$ & $1,94 a$ & $3,66 a$ & $7,54 \mathrm{bc}$ \\
\hline 140 & $1,48 a b$ & $1,85 a$ & $3,57 a$ & $7,88 \mathrm{ab}$ \\
\hline 160 & $1,45 a b$ & $1,92 a$ & $3,77 a$ & $7,52 \mathrm{bc}$ \\
\hline
\end{tabular}

* Médias seguidas de pelo menos uma mesma letra nas colunas, não diferem entre si, a $5 \%$ de probabilidade, pelo teste de Tukey.

No trabalho realizado por Silva et al. (2012), o gotejador G1 (1,65 L h${ }^{-1}$ ) não autocompensante, apresentou reduções nos valores de $Q$ de 42, 1 e 6\% nas pressões de serviço de 70, 210 e 280 kPa, respectivamente, quando aplicou água residuária do processamento da castanha de caju durante 160 h.

Busato et al. (2012) constataram reduções de Q de 26,13 e 27,40\% em dois tipos de gotejadores M1 $\left(2,2 \mathrm{~L} \mathrm{~h}^{-1}\right)$ e $\mathrm{M} 2\left(2,6 \mathrm{~L} \mathrm{~h}^{-1}\right)$, respectivamente, aplicando água ferruginosa. Batista et al. (2011), estabelecendo comparações entre os tempos de operação de 0 e 500 h, notaram que houve redução de $Q$ das unidades gotejadoras de 62, 22 e 61\% para águas residuárias domésticas sem tratamento, secundária e terciária, respectivamente.

Evidenciou-se reduções nos valores médios de Q de 39,11\% para o gotejador G1; de 4,14\% para o gotejador G3, e 9,21\% para o gotejador G4; exceto para o gotejador G2, que apresentou sensível aumento de vazão de 0,53\%, após 160 h de operação com percolado de aterro sanitário diluído. No tempo de operação 140 h (Figura 4), houve uma drástica redução na vazão do modelo G3 causada provavelmene pela redução parcial de vazão dos emissores.
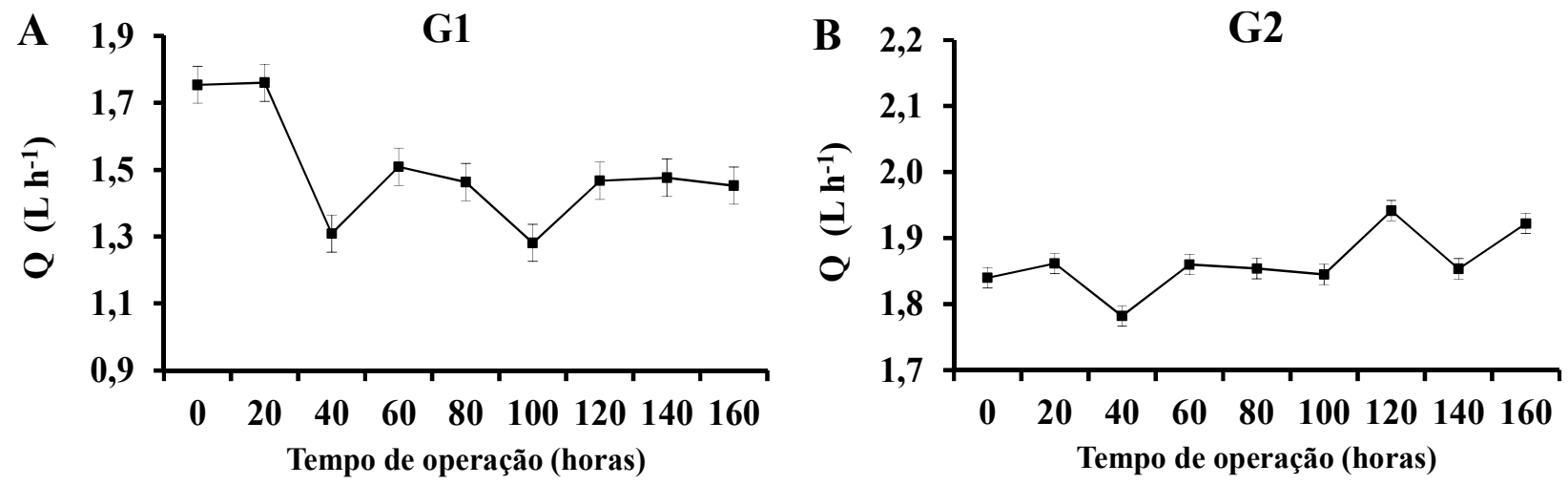

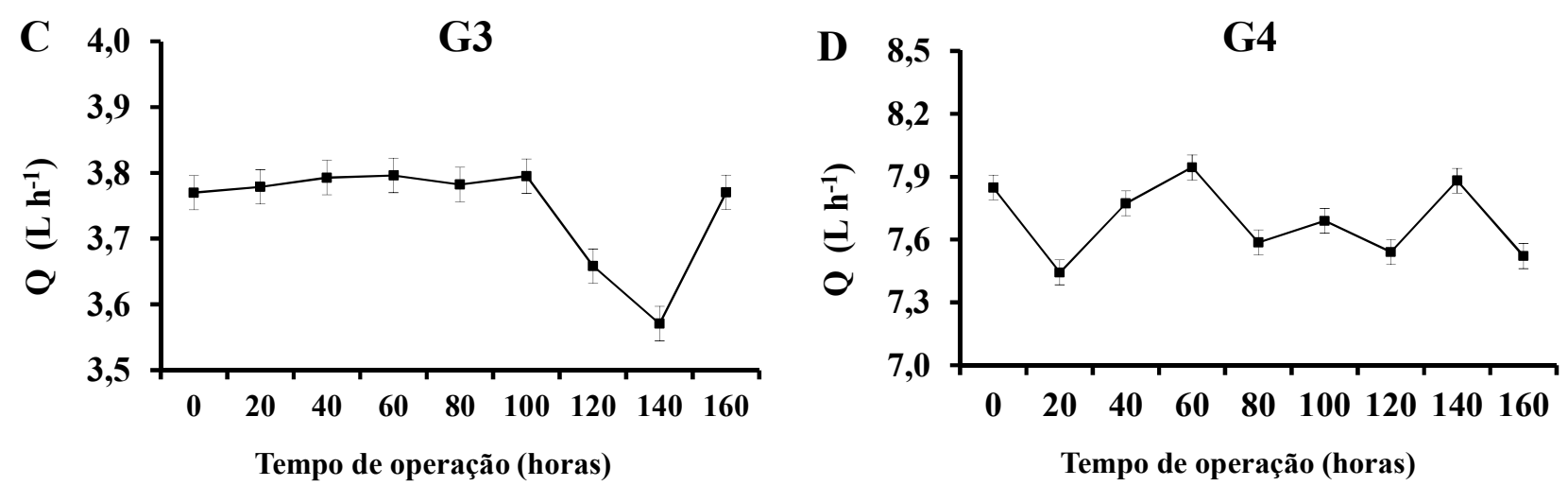

Figura 4: Valores médios e erro padrão de $\mathrm{Q}$, durante $160 \mathrm{~h}$ de operação do sistema, nas unidades gotejadoras dotadas dos quatro tipos de emissores (G1-A, G2-B, G3-C e G4-D).

O entupimento dos gotejadores reduz a eficiência dos sistemas de irrigação, afetando suas características de operação e exigindo manutenções mais frequentes. Geralmente, a obstrução altera a vazão dos gotejadores e, consequentemente, diminui a uniformidade de aplicação de água e a eficiência dos sistemas de irrigação localizada (DAZHUANG et al., 2009; DURAN-ROS et al., 2009).

Comparando situação experimental semelhante, Costa et al. (2019) constatou redução significativa nos valores da $Q$ do gotejador $G 1\left(1,65 \mathrm{~L} \mathrm{~h}^{-1}\right)$ não autocompensante de 6,01\% na unidade gotejadora abastecida com percolado de aterro sanitário diluído e submetida à pressão de $140 \mathrm{kPa}$.

Silva et al. (2014) ao trabalharem com unidades gotejadoras aplicando água residuária tratada da indústria da castanha de caju sob pressões de serviço, notou-se que após $160 \mathrm{~h}$ de operação não é recomendada o uso de gotejadores de baixa vazão nominal $\left(\leq 1,6 \mathrm{~L} \mathrm{~h}^{-1}\right)$ e maior comprimento de labirinto ( $\geq$ $58 \mathrm{~mm}$ ). Entretanto, Morata et al. (2014), obtiveram resultados contrastantes, pois não foi detectado efeito significativo do tempo de operação na redução da vazão dos gotejadores, após $320 \mathrm{~h}$ de aplicação de esgoto doméstico.

Na unidade gotejadora G1, o modelo quadrático foi o que se ajustou aos dados de $Q$ em função de $T$, tendo valores de $R^{2}$ de 0,$60 ; 0,82 ; 0,85,0,85 ; 0,60 ;$ e 0,60 , respectivamente (Tabela 4). Aplicando a primeira derivada neste modelo obteve-se: o valor mínimo de $Q\left(1,36 \mathrm{~L} \mathrm{~h}^{-1}\right)$ no tempo de operação de $106 \mathrm{~h}$.

Tabela 4: Equações de regressão ajustadas às variáveis $Q\left(L h^{-1}\right)$, em função do tempo de operação $(T)$, das unidades gotejadoras para os tipos de gotejadores $(G)$ e respectivos coeficientes de determinação $\left(R^{2}\right)$.

\begin{tabular}{lll}
\hline \multirow{2}{*}{ Gotejadores } & Variável Q & $\mathbf{R}^{\mathbf{2}}$ \\
\cline { 2 - 3 } $\mathrm{G} 1$ & $\mathrm{Q} \hat{\mathrm{Q}}=1,764-0,00764^{*} \mathrm{~T}+0,000036^{*} \mathrm{~T}^{2}$ & 0,60 \\
$\mathrm{G} 2$ & $\hat{\mathrm{Q}}=\overline{\mathrm{Q}}=1,862$ & - \\
$\mathrm{G} 3$ & $\hat{\mathrm{Q}}=\overline{\mathrm{Q}}=3,393$ & - \\
$\mathrm{G} 4$ & $\hat{\mathrm{Q}}=\overline{\mathrm{Q}}=7,691$ & - \\
\hline
\end{tabular}

Nota: ${ }^{*} \mathrm{e}^{* *}$ Significativo à 1 e $5 \%$ de probabilidade pelo teste ' $\mathrm{t}$ '. $\mathrm{T}$ - tempo de operação, em $\mathrm{h}$.

\section{CONCLUSÕES}

A vazão do sistema (Q) foi obtida a cada $20 \mathrm{~h}$ de operação do sistema, até completar $160 \mathrm{~h}$ de funcionamento em todas as unidades de irrigação. Houve diferença estatística dos níveis de obstrução do gotejador G1 (não autocompensante) em relação aos demais, indicando menor suscetibilidade ao 
entupimento dos gotejadores G2, G3 e G4 (autocompensantes). Os valores de Q aprontaram o gotejador G1 como o mais sensível ao entupimento.

\section{REFERÊNCIAS}

ALMEIDA, F. D. B.; BILYK, C.; SIEBEN, P. G.. Gestão de resíduos sólidos urbanos: impactos ambientais e o processo de inclusão social dos catadores de lixo. Gest. Tecnol. Inov, Caxias do Sul, v.2, n.1, p.12-25, 2018.

BATISTA, R. O.; COSTA, F. G. B.; LOPES, H. S. S.; COELHO, D. C. L.; PAIVA, M. R. F. C.. Efeito das características do esgoto doméstico na uniformidade de aplicação de sistemas de irrigação por gotejamento. Revista Caatinga, Mossoró, v.24, n.4, p.137-144, 2011.

BATISTA, R. O.; SILVA, K. B.; SILVA JÚNIOR, M. J.; SANTOS, D. B.; CUNHA, R. R.. Performance of drip emitters for different pressures and applicationof cashew nuts wastewater. Revista DYNA, Medellín, v.85, n.204, p.38-43, 2018. http://dx.doi.org/10.15446/dyna.v85n204.64322

BUSATO, C. C. M.; SOARES, A. A.; RAMOS, M. M.; REIS, E. F.; BUSATO, C.. Dicloroisocianurato na prevenção do entupimento devido ao uso de águas ferruginosas em sistemas de irrigação por gotejamento. Semina: Ciências Agrárias, Londrina, v.33, n.1, p.49-56, 2012. DOI: http://doi.org/10.5433/1679-0359.2012v33n1p49

CELERE, M. S.; OLIVEIRA, A. S.; TREVILATO, T. M. B.; SEGURAMUÑOZ, S. I.. Metais presentes no chorume coletado no aterro sanitário de Ribeirão Preto, São Paulo, Brasil, e sua relevância para saúde pública. Caderno de Saúde Pública, Rio de Janeiro, v.23, n.1, p.939-947, 2007. DOI: https://pesquisa.bvsalud.org/portal/resource/pt/ens-20875

COELHO, D. C. L.; BATISTA, R. O.; SILVA, P. C. M.; MESQUITA, F. O.. Produção de capim elefante utilizando percolado de aterro sanitário. Bioscience Journal, Uberlândia, v.31, n.3, p.830-840, 2015. DOI: https://doi.org/10.14393/BJv31n3a2015-22400

COSTA, D. O.; VALE, H. S. M.; BATISTA, R. O.; SILVA, P. C. M.; LEMOS FILHO, L. C. A.; SANTOS, D. B.. Suscetibilidade ao entupimento de gotejadores aplicando água residuária doméstica tratada. Revista em Agronegócio e Meio Ambiente, Maringá, v.12, n.4, p.1251-1266, 2019. DOI: https://doi.org/10.17765/2176-9168.2019v12n4p1251-1266

CUNHA, M. E.; MARQUES, B. C. D.; BATISTA, R. O.; COSTA, A. G.; CUNHA, R. R.; ANDRADE, A. T. S.. Obstrução de gotejadores operando com efluente de laticínios diluído. Revista Brasileira de Agricultura Irrigada, Fortaleza, v.11, n.4, p.1517-1527, 2017. DOI: http://doi.org/10.7127/rbai.v11n400644

DAZHUANG, Y.; ZHIHUI, B.; ROWAN, M.; LIKUN, G.; SHUMEI, R.; PEILING, Y.. Biofilm structure and its influence on clogging in drip irrigation emitters distributing reclaimed wastewater. Journal of Environmental Sciences, Pequim, v.21, n.6, p.834841, 2009. DOI: https://doi.org/10.1016/S10010742(08)62349-9

DURAN-ROS, M.; PUIG-BARGUES, J.; ARBAT, G.; BARRAGAN, J.; CARTAGENA, F. R.. Effect of filter, emitter and location on clogging when using effluents. Agricultural Water Management, Espanha, v.96, n.1, p.67-79, 2009. DOI: http://doi.org/10.1016/i.agwat.2008.06.005

FERNANDES, R. K. A.; BATISTA, R. O.; SILVA, S. K. C.; OLIVEIRA, J. F.; PAIVA, L. A. L.. Vazão de gotejadores aplicando água residuária da castanha de caju. Irriga, Botucatu, v.19, n.4, p.585-597, 2014. DOI: https://doi.org/10.15809/irriga.2014v19n4p585

FERREIRA, D. F.. Sisvar: A computer statistical analysis system. Ciência e Agrotecnologia, Lavras, v.35, n.6, p.10391042, 2011. DOI: https://doi.org/10.1590/S141370542011000600001

GOMES, N. A.; ALMEIDA, M. V. A.; MELO, M. C.; MONTEIRO, V. E. D.; OLIVEIRA, R.. Influência de parâmetros físicoquímicos na composição de constituintes tóxicos em lixiviado de aterro sanitário. Revista Matéria, Rio de JaneiroRN, v.23, n.3, p.1-11, 2018. DOI:

https://doi.org/10.1590/s1517-707620180003.0489

HERMES, E.; BOAS, M. A. V.; GRIS, D. J.; LINS, M. A.; BERGER, J. S.. Uniformidade de distribuição na irrigação por gotejamento com água residuária de processamento de mandioca. Revista em Agronegócio e Meio Ambiente, Maringá, v.11, n.2, p.545-559, 2020. DOI: http://doi.org/10.17765/2176-9168.2018v11n2p545-559

JACOBI, P.; BESEN, G. R.. Gestão de resíduos sólidos em São Paulo: desafios da sustentabilidade. Estudos Avançados, São Paulo, v.25, n.71, p.135-158, 2011. DOI: https://doi.org/10.1590/S0103-40142011000100010

KLEIN, F. B.; GONÇALVES-DIAS, S. L. F.; JAYO, M.. Gestão de resíduos sólidos urbanos nos municípios da Bacia Hidrográfica do Alto Tietê: uma análise sobre o uso de TIC no acesso à informação governamental. Revista Brasileira de Gestão Urbana, v.10, n.1, p.140-153, 2018. DOI: https://doi.org/10.1590/2175-3369.010.001.ao10

LO MONACO, P. A.; MATOS, A. T.; MARTINEZ, H. E. P.; FERREIRA, P. A.; RAMOS, M. M.. Características químicas do solo após a fertirrigação do cafeeiro com águas residuárias da lavagem e descascamento de seus frutos. Irriga, Botucatu, v.14, n.3, p.348-364, 2009. DOI: https://doi.org/10.15809/irriga.2009v14n3p348-364

MATOS, A. T.; SILVA, D. F.; Lo MONACO, P. A. V.; PEREIRA, O. G. Produtividade e composição química do capim-tifton 85 submetido a diferentes taxas de aplicação do percolado de resíduo sólido urbano. Engenharia Agrícola, Jaboticabal, v.33, n.1, p.188-200, 2013. DOI: https://doi.org/10.1590/S0100-69162013000100019

MESQUITA, F. O.; ALVES, S. M. C.; BATISTA, R. O.; DANTAS, T. B.; SOUZA, L. D.. Desempenho de gotejadores aplicando percolado de aterro sanitário diluído. Irriga, Botucatu, v.21, n.1, p.156-171, 2016. DOI: https://doi.org/10.15809/irriga.2016v21n1p156-171 
MORATA, G. T.; DANTAS, G. F.; DALRI, A. B.; PALARETTI, L. F.; FARIA, R. T.; SANTOS, G. O.. Entupimento de gotejadores com uso de efluente de esgoto sob dois sistemas de filtragem. Revista Brasileira de Agricultura Irrigada, Fortaleza, v.8, n.2, p.86-97, 2014. DOI:

http://doi.org/10.7127/rbai.v8n200227

PUIG-BARGUÉS, J.; ARBAT, G.; ELBANA, M.; DURAN-ROS, M.; BARRAGÁN, J.; CARTAGENA, F. R.; LAMM, F. R.. Effect of flushing frequency on emitter clogging in microirrigation with effluents. Agricultural Water Management, Madrid, v.97, n.6, p.883-891, 2010. DOI:

https://doi.org/10.1016/j.agwat.2010.01.019

RENOU, S.; GIVAUDAN, J. G.; POULAIN, S.; DIRASSOUYAN, F.; MOULIN, P.. Landfill leachate treatment: Review and opportunity. Journal of Hazardous Materials, Madrid, v.150, n.3, p.468-493, 2008. DOI:

https://doi.org/10.1016/j.jhazmat.2007.09.077

SETIYANTO, H.; SIMBOLON, I. B. L.; ZULFIKAR, M. A.; AMRAN M. B.; BUCHARI, B.. Comparative study on leachate in old and new municipal solid waste landfills at BandungIndonesia: multielement minerals and other analysis. European Journal of Scientific Research, New York, v.79, n.2, p.159-165, 2012

SILVA, K. B.; BATISTA, R. O.; COELHO, D. C. L.; MARQUES, B. C. D.; MESQUITA, F. O.; CUNHA, J. L. O.. Vazão de gotejadores aplicando esgoto sanitário tratado e prevenção do entupimento com catalisador enzimático. Revista em Agronegócio e Meio Ambiente, Maringá, v.12, n.2, p.679-
699, 2019. DOI: https://doi.org/10.17765/21769168.2019v12n2p679-699

SILVA, K. B.; SILVA JÚNIOR, M. J.; BATISTA, R. O.; SANTOS, D. B.; BATISTA, R. O.; LEMOS FILHO, L. C. A.. Irrigação por gotejamento com água residuária tratada da indústria da castanha de caju sob pressões de serviço. Semina, Londrina, v.35, n.2, p.695-706, 2014. DOI:

http://doi.org/10.5433/1679-0359.2014v35n2p695

SILVA, L. P.; SILVA, M. M.; CORREA, M. M.; SOUZA, F. C. D.; SILVA, E. F. F.. Desempenho de gotejadores autocompensantes com diferentes efluentes de esgoto doméstico. Revista Brasileira de Engenharia Agrícola e Ambiental, Campina Grande, v.16, n.5, p.480-486, 2012. DOI: https://doi.org/10.1590/S1415-43662012000500003

SOLIANI, R. D.; KUMSCHLIES, M. C. G.; SCHALCH, V.. A gestão de resíduos sólidos urbanos como estratégia de sustentabilidade. Revista Spacios, Caracas, v.40, n.3, p.1-9, 2019.

SONG, P. L. I, Y.; ZHOU, B.; ZHOU, C.; ZHANG, Z.; LI, J.. Controlling mechanism of chlorination on emitter bioclogging for drip irrigation using reclaimed water. Agricultural Water Management, Madrid, v.184, n.1, p.3645, 2017. DOI: https://doi.org/10.1016/j.agwat.2016.12.017

UEHARA, S. C. S. A.; VEIGA, T. B.; TAKAYANAGUI, A. M. M.. Gerenciamento de resíduos de serviços de saúde em hospitais de Ribeirão Preto (SP), Brasil. Revista Engenharia Sanitária e Ambiental, Fortaleza, v.24, n.1, p.121-130, 2019. DOI: https://doi.org/10.1590/s1413-41522019175893

A CBPC - Companhia Brasileira de Produção Científica (CNPJ: 11.221.422/0001-03) detém os direitos materiais desta publicação. Os direitos referem-se à publicação do trabalho em qualquer parte do mundo, incluindo os direitos às renovações, expansões e disseminações da contribuição, bem como outros direitos subsidiários. Todos os trabalhos publicados eletronicamente poderão posteriormente ser publicados em coletâneas impressas sob coordenação da Sustenere Publishing, da Companhia Brasileira de Produção Científica e seus parceiros autorizados. Os (as) autores (as) preservam os direitos autorais, mas não têm permissão para a publicação da contribuição em outro meio, impresso ou digital, em português ou em tradução. 